\title{
Integration of learning for refugee and migrant students: VET teachers' practices through practice theory lens
}

\begin{abstract}
The study reported here used a practice theory lens to understand vocational education and training (VET) teachers' current practices in supporting integration of learning in educational institutions and workplaces - specifically for refugee and migrant students. A case study was conducted with ten teachers delivering aged care programs in South East Queensland, Australia and in a municipality in West Sweden. During in-depth interviews teachers were asked to explain the enabling and challenging aspects of their practice, and specific strategies they used to support refugee and migrant students with integration of learning in the two main sites. Analyses of data concentrated on understanding three types of arrangements (culturaldiscursive, material-economic and social-political) in the practice architectures at the two learning sites. Teachers in both countries extended beyond their everyday pedagogical approaches to support integration of learning and meet the specific needs of refugee and migrant students. Their teaching practices comprised interdependent practices of VET and aged care in two settings, each with distinct ecologies of practice. Their narratives reflect contestations between practice traditions of aged care practices in Australia and Sweden, and students' understandings and reflections of practices in their birth countries. We conclude that teacher training and adjustments to these arrangements can bridge contestations between the enacted and experienced curriculum in the two sites.
\end{abstract}

\section{Introduction}

Enactment and engagement of any vocational education and training (VET) curriculum typically takes place in complementary physical and social settings of educational institutions and workplaces, each with different purposes, goals, processes and practices. Students are required to engage in this duality and reconcile experiences gained in each site to appropriately integrate learning as they develop vocational competence to become productive members of the workforce, and of society. We interpret integration at two levels: i) From a social-political perspective as assimilation into society and transition into employment; and ii) Pedagogically as intentional and effortful intellectualisation and appropriation of vocational knowledge, skills, dispositions and 'vocational being' into everyday work - within circumscribed particularities of different settings. Integration comprises cognitive, behavioural and social aspects. Individuals therefore assimilate what is learnt in two main 
practice settings - educational institution and workplaces. In the main, effective integration rests on the efforts of students because it is they who engage, experience and learn (Billett, 2009). Teachers, among other agents who support students' learning, play a crucial role in designing and arranging opportunities in ways that facilitate integration of experiences gained in different sites.

On the whole, intentions for integration are conceptualised and framed around national systems of VET and its purposes - typically reflected in the curriculum. Accordingly, as vocational education systems transform in their manifestations, purposes and practices so do the purposes and processes for integration of learning in different sites (Billett, Wärvik and Choy, 2018). Whether vocational education is based predominantly in educational institutions (eg. in Sweden and Finland), at workplaces (eg. through apprenticeships as in Germany and Denmark) or is a blend of vocational education in colleges and workplaces (eg. in Switzerland, Austria, Holland and Australia), integration of learning in the two settings underpins the curriculum for any of these models of delivery.

The point of departure in the case of refugee and migrant students is that they have specific needs not just for routine classroom learning, but also integrating learning in work sites that are socially and culturally foreign to them. They bring with them rich sets of knowledge and knowing (personal epistemologies) (Billett, 2009), and social-cultural competencies and work practices that are often in contestation with interpretations and work practices in their host countries. Teachers are therefore compelled to provide additional support to help students cross several boundaries, albeit within the constraints of existing curriculum and resourcing, and with limited or no additional training in how to prepare refugee and migrant students for working life (Lasonen and Teräs, 2016; Teräs and Lasonen, 2012).

Our focus here is on teachers of aged care courses and the aim is to gain an insight into these teachers' practices fo integrating refugee and migrant students' learning in educational institutions and workplaces. To understand the shaping of teachers' practices we have turned to the theory of practice architectures developed by Stephen Kemmis and his colleagues (Kemmis \& Grootenboer, 2008; Mahon, Fransisco \& Kemmis, 2017). We have used three types of arrangements: i) cultural-discursive; ii) material-economic; and iii) social-political, as analytical resources, typified in practice architectures as enabling and constraining features. 
Cultural-discursive arrangements shape and make possible specific "sayings" comprising professional vocabulary that make possible the language for participants to talk about their work practices. The sayings are shared by participants to describe, interpret and justify the practice (Kemmis et al. 2014; Kemmis 2009), and cultivate a common understanding. Material-economic arrangements encompass physical and economic realities which shape the practice. They make possible specific "doings" - activities completed in the course of the practice. The social-political arrangements reflect the social relationships and power ("relatings"). These arrangements make possible the relations between persons, the artefacts and professional cultures. According to Kemmis and Grootenboer (2008), the sayings, doings and relatings hang together in a practice. (For more details on practice architectures, refer to Kemmis et al. 2014; Kemmis 2009). These dynamics and the interactions between them configure the existence of each work site. Students are expected to engage and become enmeshed in these environments and learn how to function in a vocation. This is understandably challenging for all, but more so for migrant and refugee students. Hence our interest in the following two research questions: i) How do teachers navigate through practice architectures to support students? ii) What types of arrangements enable and constrain teachers to facilitate integration of learning for refugee and migrant students?

The paper is set out as follows: First, we outline the concept of integration. Second, we describe how practice theory is used to understand teachers' practice. Third, we explain the method, followed by a brief description of the Swedish and Australian VET systems and arrangements for integration that foreshadow the background of the case study sites. This follows a summary of teachers' current practices in supporting refugee and migrant students with integration of their learning. We conclude that teacher training and adjustments to these arrangements can bridge contestations between the enacted and experienced curriculum in the two sites.'

\section{Integration of learning in different sites}

At a social and political level integration for refugee and migrant populations refers to assimilation and participation in society and the world of work through paid employment (e.g. Prokic-Breuer and McManus, 2016; Salant and Benton, 2017). Governments have a particular economic interest in these newcomers moving swiftly from welfare dependency into employment as soon as possible. Many are referred to vocational education and training as a 
pathway into employment especially in industries such as aged care where there is high demands for skilled workers (Webb, Faine, Pardy and Roy, 2017; Wheelahan and Moodie, 2017). Education is considered an investment in a person (human capital), not only for economic reasons, but also for enhancing chances in life and possibilities of living an independent life. Such aspirations of integration are worthy, but this is not the aspect of integration we focus in this paper. Our point of departure is a pedagogic interpretation, meaning integration of learning in educational institutions and workplaces which subsequently leads to employment and supposedly a good life.

From a learning perspective, integration is the 'intellectualisation of work associated with modern, integrated production systems' (Svensson, Ellström and Åberg, 2004, p. 479). It takes place at two levels. At the individual level, it refers to cognitive processes of transferring and connecting knowledge gained in different sites. Contextually, integration refers to engaging in tasks, using appropriate tools and situated communication to make vocational meaning for distinct practice 'ecosystems'. We adopt Kemmis et al.'s (2012), interpretation of practice setting as an 'ecosystem' where individuals interact and interrelate with each other and the artefacts within. As a precondition, integration necessitates agency and effort on the part of learners and interlocutors who facilitate interactional processes to appropriate and 'ecologise' vocational knowledge, skills and dispositions that match with practice cultures of particular ecosystems. Thus, integration is intra as well as inter subjective, but demands connectedness with particular practices. We see the act of integration as intentional, deliberate and premediated in that the learner and those who assist with integration have a purpose in mind, that is, learning to constructively connect school based and everyday work knowledge. Such interactions are circumscribed by the particularities of given vocations or work sites in which the practice architectures prefigure how integration will fit into the ecosystem. Prefiguration anticipates cognitive as well as behavioural and affective changes that demonstrate comprehension and actions for what is mutually established as good vocational practice. As newcomers to particular practice sites VET learners begin by engaging peripherally (Lave \& Wenger, 1991) to understand and learn the norms. Importantly, they need to understand and appreciate the practice architectures and ecologies of practices in order to cross boundaries and thresholds (Timmermans, 2014) and enhance learning and integration. 
Given that integration calls for knowledge flow between the sites (VET institutions and workplace settings), each with its own practice cultures, at a micro level it makes integration bi-cultural. At a meso level, it is also inter-cultural - enmeshing reciprocal exchange of knowledge across and within each practice setting. Similarly, at a macro level integration is also multi-cultural because it needs to consider variations in cultural practices within a particular vocation and within sites, invariably influenced by ethnic cultures of participants, as well as 'classed' cultures. Cultural contexts aside, interactions and exchanges are mediated in semantic spaces, and realised through the 'sayings' - language of the vocation (vocational literacy), discourses of the practice, and a common communicative mode (ie. language for exchange, eg. English or Swedish). Respectively, we suggest that communicative interactions for integration is trans-lingual. The cultural and language tools typically authenticate the 'sayings' and thinking for 'symbiotic' and 'reciprocal' relations within and across different sites such that students are influenced by the practice and at the same time influence practice during their interactions in a given ecosystem. Moreover, all engagements have moral appropriateness, and are socially and politically enacted in specific ways (eg. under the codes of practice and regulations), in different settings and circumstances. This makes teachers' practice of supporting integration across sites rather complex. We used a practice theory lens to unveil the complexity of their practice.

\section{Practice architectures as a theoretical point of departure}

There are practice theories of many different kinds (see Nicolini, 2012; Schatzki et al, 2001). Most commonly, practice-theories draw attention to trivialities of everyday life, the mundane aspects that most often are taken for granted (Choy, Edwards-Groves and Grootenboer, 2017). In their theory of practice architectures, Stephen Kemmis and his colleagues developed analytical tools to characterise explicitly what is happening in the routines of the everyday life of a particular site and the conditions under which they occur.

To illuminate and give emphasis to the complexities of teachers' practice with integration of learning between educational institutions and workplaces, we chose practice theory to provide a background of the study. Our analytical focus is on teachers' practice -enactment of work to realise good teaching - praxis that is collectively shared with other teachers, students, those who support students' learning in the workplace, and others they interact with. Praxis in this instance uses Freire's view which has a moral and political connotation, embracing both 
materialities and historicity, traditions that guide education for the good of the people concerned. Thus, Kemmis (2010) and Mahon, Kemmis, Fransico and Lloyd (2017) argue that teachers' practice is oriented by praxis. Practice theory gives us a tool to embrace discursive and material conditions, and power relations, not as dualities, but as an ongoing enmeshment that is formed in and through interactions between the participants (eg. teachers, students, managers, support staff, workers in sites where students gain experience). A practice comprises corollaries of language, meanings, actions, interactions etc. in a particular site, but at the same time is also a generator of language, meanings, actions and interactions. In this sense, practice can be both reproductive that is, repeating existing practices, and be transforming and producing new practices. It is the individuals involved who become the architects of their practice as they perform the practice, meaning that there is a stabilising robustness through agency and inventions (Nicolini, 2012). In short, practices "put people (and things) in place" (Nicolini, 2012, p. 6), as they are situated in culture and history. They are not 'silent' actors, but carriers and reproducers, and/or disruptors of societal norms, materialities and power relations. Nonetheless, Kemmis and Grootenboer (2008) remind us that arrangements in practice architectures also enable and constrain certain ways of talking, actions, and relations with others.

How well students integrate learning at educational sites and in the workplaces is therefore influenced and shaped by what Kemmis, Edwards-Groves, Wilkinson and Hardy (2012) describe as practice 'architectures', prefigured by three types of arrangements: 'culturaldiscursive', 'material-economic' and 'social-political'. Practice architectures are intermittently transformed through consensus, thus practice architectures are never static practices unfold in the course of routine happenings. Within the ecological dynamics of particular practice settings, learning cannot happen organically, and there are also thresholds to transcend. That is, students need agency and tailored pedagogical practices to help them navigate and reconcile learning in the ecologies of practices. As such it becomes imperative for teachers to design and enact curriculum that offers opportunities for students to gain experiences and develop competencies for their chosen vocations. It was along these imperatives that the research reported here was designed to understand teachers' practices in supporting refugee and migrant students' integration of learning in educational institutions and workplaces. A critical analysis of the details provides an understanding of practice as a whole. The daily happenings are conceptualised by Kemmis and Grootenboer (2008) as the 'sayings', 'doings' and 'relatings' of the practice that hang together in a specific project, that 
is, the motive of the practice. The motive (eg. integration of students' learning experiences between educational institutions and workplaces) defines and directs particular aspects of teachers' practice.

According to Kemmis et al. (2014), actors involved in a practice are shaped by and engaged in the shaping of practice architectures that enable or constrain the 'architecture' of a practice. These resources or tools are the specific 'cultural-discursive', 'material-economic', and 'social-political' arrangements that hang together and give meaning and sense to each other. They are complementarily configured in specific ways to constitute and create rationalities of a particular practice, but also to enable innovation and variation. Cultural-discursive arrangements are resources that enable and constrain what is possible and relevant to say in a particular practice, for instance the vocabularies associated with the vocation and with the teaching of the vocation. Material-economic arrangements are both human and non-human resources, division of labour, economic conditions, materials available for teaching and integration etc. Social-political arrangements enable and constrain how people relate to each other within a practice community, but also between practices. These arrangements can, for instance, pertain to rules and norms that can be both implicit and explicit, and underpin the governing relations between teachers and students (Kemmis \& Grootenboer, 2008) as well as workplaces where students gain vocational experiences. The social-political arrangements in workplaces form important considerations for teachers to negotiate for integration. They are expected to prepare students to navigate and reconcile what they learn in VET institutions and the workplaces. Thus, we maintain that teachers are engaged in 'ecologising' of practices that embrace and contextualize the 'sayings', 'doings' and 'relatings' of each site and that connect the practices in ways that make sense in both sites.

Practice architectures and arrangements are therefore seen as stabilized resources, yet also as entities open for change. They evolve in response to external pressures, generally when subjected to external forces. The practice of aged care for instance is organized in a complex web of actions, embracing language, material conditions, and relationships between staff, residents, family and socio-cultural surroundings of the facilities. Teachers have to take into account these in conjunction with a web of actions at their educational institution. They are well trained in supporting integration between learning in educational and workplace settings, and their refugee and migrant students need additional help. This requires both teachers and 
students to enmesh multi-cultural aspects of integration. Thus both become learners as they mediate routine and non-routine, familiar and unfamiliar thresholds.

Our project searched for teachers' practices and how they resolved challenges with supporting integration of learning for refugee and migrant students completing aged care courses. When in the workplace students are expected to learn about practices that include making judgements within changing situations of residents and the aged care facility; developing the types of dispositions typical of aged care workers; recognising and responding to what matters in everyday practice; and how to conduct oneself in ways acceptable to the worksite community. Their learning stimulates ontological transformations. Their engagement is expected to instantiate learning to reproduce practices and at the same time contribute to its evolution by creating and innovating new ways of doing things (Schatzki, 2017). These are not easily done when refugee and migrant students struggle with cultural-discursive, materialeconomic and social-political arrangements in educational institutions and in aged care facilities.

\section{Method}

This study employed a case study approach. In-depth interviews were completed with ten teachers, five from Technical and Further Education (TAFE) in Australia and five from a private provider of adult municipal education in Sweden. All participants had lengthy teaching experiences (3 -16 years), except one Swedish teacher who had recently completed her teacher training. The educational backgrounds of Australian and Swedish teachers were rather different: Australian VET teachers are required to demonstrate lengthy experiences in their occupational areas first and complete a VET teaching qualification (eg. Certificate IV in Training and Assessment as a minimum). Health care teachers in Sweden first graduate as licenced nurses and additionally have a nurse specialist education (equivalent with SeQF 6), and then complete a VET teacher training program at a university. This was the case for the four Swedish teachers interviewed for the study. The fifth Swedish teacher obtained health care education at upper secondary school level, had three years' experience as an assisting nurse, and then went on to obtain a VET teacher education at the university. At each site, two teachers were male. All teachers were educated in Australia and in Sweden respectively. 
The sites in each country were selected for convenience and teachers were contacted through networks known to the authors. In both sites, the head of the institution was contacted for approval to conduct the study. Teachers were informed about the study through internal communication and invited to participate. Ethical clearance for the study in Australia was obtained from the first author's institution, and guidelines from the Swedish Research Council in Sweden were followed.

In both countries, the interviews took place at the educational institutions. The Australian interviews were conducted in English by both authors, while the second author interviewed the Swedish teachers in the local language (Swedish). The Australian interviews lasted about an hour and the Swedish interviews took around two hours. The interviews covered the following themes:

- The teaching practice in general

- Challenges with refugee and migrant students

- Nature of assistance to these students

- Ways integration of learning between educational institution and work place can be improved

- Agents who support students' learning and integration

- Enabling and constraining aspects of integration.

The conversations were recorded and transcribed. Parts of the Swedish interview were translated to English to allow joint analysis.

The first step of the analysis focused on identification of themes around the "sayings", "doings" and "relatings". Four themes were identified in the interview transcripts:

1. Interacting with the students, residents, staff and other service providers, using the technical and everyday language

2. Carrying out the routines of teaching and visiting students in the workplace and assessing, and liaising with the site to maintain support for students (i.e. curriculum related activities and work)

3. Relating to other agents, such as managers, supervisors, nurses and other aged care workers in the site, and also other teachers (i.e. power and solidarity)

4. Ensuring good teaching where themes 1,2 and 3 hang together in a specific project of the site (Kemmis and Grotenboer, 2008) - integration of learning between two sites.

The second step was to interpret the content in the themes and alignment to specific culturaldiscursive, material-economic and social-political arrangements, as presented to us by the teachers during the interviews. More specifically, the analysis paid close attention to ways of talking about integration of learning for these groups of students, how the use of material 
objects were described, as well as relationships between people. Finally our analytical focus turned to how these enabled and constrained the "sayings", "doings" and "relatings", that is, what was possible to say, do and relate to in the practice of teaching (Kemmis, Wilkinson, Edwards-Groves, Hardy, Grootenboer and Bristol, 2014).

Our intention was not to make a comparison between the two nations, but to illustrate how practice theory can be used to understand teachers' practices and challenges with integration of students' learning between school and work. The Swedish adult education institution offers education in general school subjects (basic and upper secondary school levels) as well as vocational subjects (at upper secondary school level), and Swedish language course for immigrants. As a consequence of an increasing number of refugees, and political demands for shortening the period it takes to become part of the workforce, language training often is integrated with vocational adult education in Sweden. The language of instruction is Swedish, but pre-requisites in the Swedish language for entering vocational adult education in Sweden can be quite low. To compensate this, Swedish language teachers support VET teachers if their students need language assistance, meaning that a VET-teacher and a Swedish teacher work together in class - around nine hours a week. In Australia students must meet prerequisites for the English language. However, if there is a need for language support, it is not offered in conjunction with vocational courses - as is the case in Sweden. The separate languages course may have implications for developing vocational literacy in a more integrated way, which is quite different to learning a language for everyday communication.

Swedish teachers teach only in the adult education institution, have little direct contact with workplaces and rely on the workplace supervisors. Swedish students spend around four weeks every semester in a workplace setting, and teachers make one contact visit during this period to meet the student and the workplace supervisor. The work settings where Swedish students gain experience can be very different from each other so teachers have to carefully assess what kind of vocational knowledge their students get access to and if needed, compensate for the missing knowledge when they return to the school setting. Some of the Swedish students get their work experience in an acute care setting, others in aged care settings (which is a main focus here).

Furthermore, Swedish teachers are pressured by procurement processes that call for efficiency and their success measured once graduates are able to secure employment (Fejes, Runesdotter and Wärvik, 2016). 
Australian teachers support learning in the aged care facilities where students are on placement to gain work experience. Teachers visit the sites regularly, but spend little time actually facilitating learning. They rely on experienced supervisors and workers to assist with student learning. Their regular visits to observe and support students present opportunities for teachers to gain currency of aged care practice.

Organizing courses that are flexible in time and space as well as meet individual needs makes teachers' tasks quite a challenge. This is because individualization demands a tight connected system where students are fully aware of what is expected of them, do their tasks the way they are supposed to, and also connect to and support institutionalized procedures (Henning Loeb and Lumsden Wass, 2014). The findings in the next section provides an empirical account of VET teachers' practices and challenges.

\section{Findings}

\section{VET teachers' practice architectures}

The Australian and Swedish teachers' narratives describe contestations of curriculum processes and practice traditions in educational institutions and in aged care facilities. Although the context in which they deliver the curriculum is different, teachers from both nations seem to experience similar kinds of challenges when supporting refugee and migrant students. Accordingly, the findings from the case studies are presented as a whole, and only those aspects that are distinct to Australian or Swedish contexts are identified where relevant.

The findings show that teachers' approaches extended beyond their everyday practices that are designed for domestic students, to meet the specific needs of refugee and migrant students. Their efforts were directed to empower students to become agentic learners and cross thresholds that are new to them as they developed competencies for aged care work. In doing so, teachers recognised the democratic rights of these new comers who were grappling with integration into society in their adopted countries. The teachers also recognised the diverse needs of students, and that refugee and migrant students were not a culturally homogenous group. A group of students can have very different ideas that influence their learning, as explained below. 
Migrants are diverse... You can't treat them as a single group... what they have in common is that they don't have the Swedish language' (Swedish teacher).

Teachers acknowledge that students get somewhat 'stirred' into aged care practice during their placement, but are not always seamlessly embedded in due to cultural and language challenges. Delivering personal care, showering client, would mean something completely different if they came from Asian countries... We have managers saying there's a communication problem. They can't understand (Australian teacher).

Like their students, teachers too struggle with cultural and language competences that constrain the flow of what is to be learnt at the two sites. Students class it as a task rather than have the understanding as to why are they showering that person. What they should be doing while they're showing that person, which is communicating, checking their skin, checking orientation...' (Australian teacher). They are constantly trying to work out new ways to perform 'good teaching'. Teachers also recognise the importance of educating health care workers about different cultures in contemporary society and ways they can help refugee and migrant students to integrate and learn what matters in aged care practice. They fully appreciate that engagement and interactions have moral appropriateness, are socially and politically enacted in specific ways in different settings and circumstances of aged care practice.

In the sections below we frame teachers' practices from a practice theory perspective and attempt to make sense of their work in terms of three types of arrangements: i) culturaldiscursive; ii) material-economic; and iii) social-political. These arrangements prefigure conditions for student learning.

\section{Cultural-discursive arrangements and practices of 'saying'}

Cultural discursive arrangements relate to the practice cultures and the communicative spaces for meaning making. Particularities of aged care practice create the social cultural setting for the industry and this is what teachers try to replicate in their teaching clinics by creating spaces for meaning making. The curriculum for the aged care program includes practices of aged care (vocation) for mainstream population and cultural context of personal care which teachers found was in contestation with what refugee and migrant students know and 
understand. For instance, one teacher explained that 'Discrete work tasks are well performed - see, copy, do - but lack the cultural understanding' (Australian teacher). Refugee and migrant students who are new to the country are often unfamiliar with teachers' expectations of reflection and analyses in educational contexts: 'yes a brain is a brain if you understand what I mean, but if we discuss ethics of care ... it has been a journey for both them and me' (Swedish teacher). These examples illustrate how culturally embedded specialist language of the vocation might constrain cultural-discursive arrangements. Students' actions seemed to be constrained by their cultural practices and values based on what they learnt and know from practices in their birth countries. For instance, there were cultural codes for touching bodies of older people. Then there were codes for different genders. Asking the right question, such as 'If I was looking after your Mum or Dad, what would you like me to know?' (Australian teacher), prompts better responses from students, and this enables teachers to learn and work out bridging strategies.

Navigating the social-cultural situations during role plays in simulated training at clinics within the educational settings, with familiar others (teachers and students), was less difficult for refugee and migrant students. These were controlled situations, directed by teachers. However, teachers have little control over the everyday situations in the aged care facilities where there are other unanticipated impositions. For instance, Australian students are frequently told 'Forget what you learnt at TAFE, this is how we do things here.' This disorients students who begin to question the difference between the teaching in the educational institution and the 'real' world where short-cuts and compromises can breach regulations. Swedish teachers also described similar instances that constrained the bi-cultural flow of knowledge between the two main sites. Students tell them "they don't do it in the way you have taught me."

In these situations, but also in general, teachers rely heavily on the supervisors to demonstrate good practice. However, to maintain good relations with the workplaces, teachers feel compelled to allude to malpractice with the supervisors if students bring this to their attention.

The mismatch between what is learnt in the VET institutions and in the aged care facilities adds to further confusion arising from students' own backgrounds (language, ethnic, cultural, educational, professional backgrounds). These present a different set of challenges for 
teachers to support students with crossing several boundaries - social, cultural, professional, language etc. Given that students need to accommodate themselves within the everyday activities of the workplaces where they participate in the sharing of tasks for a common purpose, the tendency is to diligently conform to the routines as a given. The significance of 'sayings' is evident in the way teachers describe how they advise students to pay particular attention to the talk occurring in the work sites - 'ways in which staff talk to residents and how they relate to their families or other service providers and observe the cultural conduct in the workplace.' However, they are not there to guide them on a daily basis. To understand the nature and scope of learning, teachers have to rely on students' reflections of their experiences. The debriefings when students return from practical periods gives them a fair idea of what students learn and the types of challenges they experience. This calls for specific pedagogical strategies to draw on, analyse and appraise those experiences for individuals. However, time constraints of the curriculum limit how much teachers are able to accomplish. Besides, not all teachers have the expertise to fully assist refugee and migrant students because they have not received specific training for this cohort, as one teacher explained:

This is a big difference ... the tools that I learned during the teacher education, and the tools that I need today, to be able to achieve the same ... and here I point especially to the issue of language development. To reformulate so that everything can be understandable, so that the end product is the same as it was earlier (Swedish teacher).

Teachers' practices involve interacting with colleagues, students, aged care residents, staff and other service providers. They use specialist and culturally appropriate discourses of good aged care, of resident comfort, students completing routine tasks for good care, and assessment. These reflect daily happenings. Teachers try to mediate contradictory aspects of the curriculum when they visit the sites to monitor students' progress. Where the affordances inadequate, they relocate students to new sites. In this way, they respond to disparities in practices and affordances. Their work is ecologically dependent on practices where their students gain experiences so they have to accommodate changes in the interest of the students' development. It is the strong partnership and regular contacts they make with the sites that enable their efforts at the contextual level, but often the challenge lies with integration at the cognitive level. This is due mainly to language-related concerns. 
The cultural discursive arrangements are shaped by a material world that forms particular conditions for teachers' practices and what is possible to do. This is described by Kemmis et al. (2012) as the material-economic arrangements. For teachers the material-economic arrangements are determined by the curriculum and resourcing. Australian teachers are constrained by a short curriculum delivered over a period of 14 weeks for a Certificate III qualification. Students enrol in fulltime studies, attending courses for up to three days per week. A three week placement follows the 14 weeks of study at the VET institute. Teachers deliver a curriculum that is resourced for mainstream students. For instance, there is no inclass language support for refugee and migrant students. According to VET teachers, 'Students often use translators, but don't understand the everyday language to make vocational meaning'. The clinical settings in their institutions are generally well equipped to replicate what is available in aged care facilities. Delivery takes place in mixed groups of domestic, refugee and migrant students. Teachers negotiate placements for students, although there is no training agreement like for apprentices. These arrangements are based on good will and relations that teachers have built with the local aged care sites.

The Swedish curriculum is longer than the Australian: three semesters for the regular classes and four semesters for classes with integrated language support. You work with the texts in a different way in the two groups. With language support, ... you look at the texts, and rephrase them, use synonyms, simplify the sentences. Each semester students spend four weeks in a workplace. Teachers visit the workplace only once during a work placement - for a follow up meeting with the student and the supervisor. Given that teachers have limited contact with the workplaces, students are dependent on good supervisors, a condition that often creates problematic situations that are out of the teachers' control. One such aspect relates to students' language skills. Earlier, when students failed and didn't reach the goals, it often was because of big absence, lack of interest and initiatives. This has now changed, now it is about the language, they fail because they are unable to communicate in the workplace (Swedish teacher)

In classroom settings, they work alongside a language teacher, but when in a workplace, students do not have access to this kind of support. Workplace supervisors are expected to handle these situations, but are not trained in language support. One of the teachers talked about a gap between the work of supervisors and the VET teachers that embrace more than only the language issue: 
There has always been a gap, and the gap is still there, but you should have more interaction [between workplace supervisor and the teacher]. They are expected to take a course in training for supervisors, but still they have many questions ... It [the curriculum] can sometimes be confusing for the supervisors (Swedish teacher).

Generally, caring situations are socially and culturally demanding so lack of language support negatively impacts on integration of students' learning in the two settings. These features prefigure how the sociality of learning transpires. During work placement, students are expected to carry out the everyday routines and to integrate what is learnt in_school and what they experience at work. In both nations, teachers strived to overcome organisational cultural barriers in the two institutional settings however, with limited material resources.

Teachers describe how they routinely tried to create opportunities to internalise and intentionalise learning for students. We find out other ways to do things, and work with other kinds of tools, to reach what we want to accomplish in our teaching (Swedish teacher). In both countries the teachers mentioned the importance of simulated activities in the educational setting. They may assist them to assimilate more when they're actually out in the real workforce (Australian teacher). However, workplaces are very different from each other and students' learning is shaped by different conditions of the sites. Even so, supervisors and their ability to support students is very important, and so is VET teachers' ability to nurture good communication and relations with those in the workplaces. Within the materialeconomic arrangements, their doings include performing routine teaching tasks, visiting students in workplaces to monitor learning and conducting assessment. At their institutions, they are responsible for teaching in the classroom, and for maintaining simulated clinical practice and the resources to support this. They have less influence on the material-economic arrangements in aged care places where students gain authentic experiences.

\section{Social-political arrangements and practices of 'relating'}

Social political arrangements include relational aspects of teachers' practices to integrate learning. In both countries, there is a shortage of health care workers, hence there is directed effort from governments to encourage refugee and migrant students to consider this vocation with promises of employment. This cohort is also prioritised as they are seen to be furthest away from the labour market. Migrant centres in Australia and local labour market offices in Sweden sometimes select the vocation for the students on the assumption that students can 
easily transition into an employment after completing the VET course. This strategy is not always favourable and results in dropouts when there is a mismatch between students' interest and aspirations. 'The issue has been discussed a lot ... that we should have an introductory course, maybe 3-4 weeks, so that the students will get an idea of what the work is about'(Swedish Teacher). This is more problematic in the Swedish context for instance, where education providers are bound by the municipal procurement process under short contract periods and high dropout rates has economic consequences for the providers. ' $I t$ should be around 25 students to be an economically sound activity.' Furthermore, the number of graduates who secure employment is a key indicator in quality appraisals. Low scores can have economic consequences for the provider.

A diverse student group also requires higher levels of individualised learning to allow a full complement of learning activities and opportunities. This entails selecting workplaces and organising a customised curriculum to meet specific needs of individual students, albeit relying heavily on relations with supervisors, and transparency in processes. There is often a limited number of work placements available and the different educational providers compete for places. An Australian teacher talked about the importance of networking: I go to conferences. I'm speaking at one on Friday, so I've built up a bit of a network, if they're willing to take any of our students. The Swedish teachers instead rely on a more formalised organisation for workplacements: We have a digital platform /.../ it wouldn't work in (name of town) if all schools should call around and book places.

It is not just the social-political arrangements in educational institutions, but also in the aged care facilities that impact on students' learning and integration. Their relatings involve interactions with a range of workers in the aged care sites, as well as with other teachers to moderate the scope of activities that students are engaged in. Special relatings are needed for specific types of arrangements for refugee and migrant students. The 'everydayness' or happenings of aged care facilities fluctuates, either enabling or constraining practice. Malpractice is always a matter of concern in the context of material resourcing and time constraints, and the relation between teachers and workplace supervisors plays a significant part for integration of learning.

Earlier, the supervisors were of quite alone in their task ... but it works better now. Earlier it was like this: I called and said that I will visit you and Lotta on Monday. "Oh, but it's not possible because we have so much to do". The following year it was like "I have a student 
now and that is important. You can come whenever you want ". And this is a progress, which obviously generates a better supervision. Supervisors who are committed, motivated and not least aware of what the students bring with them from school (Swedish teacher).

An additional aspect of teachers' work is managing culturally related social issues for students. That is, female students from certain ethnic backgrounds seem to experience family pressures (eg. related to family duties) that constrain their engagement in studies and sometimes result in dropout. 'As a teacher you want to see the students complete their education, and under as good conditions as possible, so it's sad,' explained an Australian teacher who had to counsel family members about the importance of allowing time and space for women to study in order to complete courses on time. This was also a concern for the Swedish teachers.

\section{Summary}

The findings highlight that activities within the main practice settings are distributed among participants and orchestrated in ways that allows the contributions from different people to be integrated for a common purpose - students' learning. Teachers' roles include initiating students into particular forms of understanding [sayings], modes of action [doings] and ways of relating to one another [relatings] and the world of aged care. Teachers in both countries describe how they try to extend their everyday teaching practice to support integration of learning and meet the specific needs of refugee and migrant students, based on what matters for the "good of all". They are constantly navigating within a complex web of practices practice architectures - to support integration of learning between the two settings of school/training and work. Personal care is a cultural practice which forms the basis for the national educational curriculum. Teachers mediate with refugee and migrant students from diverse cultural and language backgrounds that often are in contestation with the mainstream culture, language of the vocation, and the practice of personal care. They describe how they extend beyond mainstream practice, to support the willingness of the students to learn and become employable, and the support of workplace supervisors. During interviews the teachers described their abilities to navigate the material-economic and social-political arrangements that enable and constrain teachers' practice. 
Typically, teachers' work consists of interdependent practices (of VET and aged care) in two connected settings. They operate in ecologies of practice supporting five functional roles: i) Administration of course; ii) Liaison with industry and maintenance of partnership; iii) Management of classroom and clinical practice in their institutions; iv) Empowerment and facilitation of student agency to cross thresholds and boundaries; and v) Facilitation of students' academic and social competencies.

The study reported here highlights that integration between VET institutions and workplace settings gives little consideration of what refugee and migrant students may bring to the setting. Teaching focuses on the 'right ways to do things' - a kind of 'appropriate conduct' which are different in the two sites for learning, yet bi-cultural knowledge flow needs to be maintained. Integration of learning in the workplace requires teachers to teach students how to speak well and think well (participate in the sayings), act appropriately in the material world (participate in the doings) and how to relate to others (co-operate in the relatings). The characteristic sayings demand symbolic cultural language and concerns cognitive processes. The characteristic doings are psychomotor in nature and relate to the procedural actions. The characteristic relatings are affective and are influenced by dispositions and power relations in the social field. These three intertwined composites shape the landscape or traditions. Learning is harmonised through interactions with the interlocutors (those who assist the students with learning when in the workplace) to maintain the ecological equilibrium in a practice until there are changes to arrangements in the practice architectures. The particular arrangements either enable or constrain learning in particular practice sites, and therefore the level of integration.

\section{Conclusions}

The practice theory lens was a useful tool for gaining an insight into arrangements in the practice architectures that enabled and constrained VET teachers' work on supporting refugee and migrants with integration of learning in educational settings and aged care facilities. We suggest further research with more teachers and also to hear the voices of the refugee and migrant students to obtain more in-depth understanding of the cultural-discursive, materialeconomic and social-political arrangements and how these could be engineered to create more supportive ecologies of practice that enable integration for these students. 
What we found was that the ecological practices of the sample are similar to what VET teachers do for mainstream students in delivering the curriculum for aged care courses. However, our findings suggest they are having to constantly extend their provisions for refugee and migrant students, particularly when it comes to language and understanding. In the Swedish case, the language issue has become a main concern for adult education. Teachers have access to language teachers in the classrooms and the curriculum is extended by one semester. However, language support was of little help for teachers when it came to the different cultural experiences and backgrounds. Even if they tried to solve situations they also realised that it was not so easy to detect or respond appropriately to misunderstandings.

In both countries teacher training curriculum has limited focus in integration per se or for specific support for refugee and migrant students. Yet, they teach a very heterogeneous group of students with different prospects and educational needs. Essentially teachers' roles are twofold. They are charged with educating students to meet the high vocational standards of an occupation and at the same time the education they provide needs to equip students with specific cultural competences that help them navigate into their new occupation and transcend thresholds into the labour market. This presents a challenge for teachers when there are tensions between organisational imperatives, vocational ideals and the needs of the students (Wärvik, 2013). Hence, there is a need for teachers to find creative pedagogical practices as interventions that respond to and accommodate students' backgrounds, thereby operationalising the 'experienced curriculum' for integration, and promoting social inclusion of these students who tend to be on the margins (Onsando and Billett, 2009, 2017; Teräs and Lasonen, 2012).

Thus, we propose an appraisal of the teacher training curriculum to develop competencies in the following areas to respond to the bi-cultural, inter-cultural and multi-cultural dimensions of vocational education for aged care workers:

i) Capturing and integrating what refugee and migrant students may bring to practices in the two learning settings.

ii) Empowering and facilitating student agency to cross thresholds and boundaries, and simultaneously, ffacilitating students' academic and social competencies.

iii) Supporting refugee and migrant students with mediating the communicative spaces and transcending across boundaries between education and work, and between the mainstream 
practices and other kinds of understandings, to acquire appropriate sayings, doings and relatings that are reflective of aged care practices in their adopted countries.

iv) Navigating the material-economic and social-political arrangements to secure opportunities and resources, as well as briefing interlocutors about specific types of support needed for refugee and migrant students. This kind of navigating might be challenging for teachers, given the managerial, economic and political aspects of adult education they need to mediate within the multi-cultural conditions of VET.

Overall, teachers should be encouraged to develop a critical eye that supports development of their evolving practice and respond to emerging changes. These areas of further development will better equip teachers with supporting integration for refugee and migrant students.

\section{Limitations}

The small sample size of this study could rightly be interpreted as limited. However, the indepth interviews bring out common views and challenges regardless of differences in national systems or teachers' educational backgrounds. Nonetheless, the findings confirm anecdotal records. Above all, the practice architecture theory lens has furnished helpful theoretical tools to analyse the complexities that are inbuilt in teachers' work on integration of learning between school and work for refugee and migrant student. 


\section{References}

Billett, S. (2009). Personal epistemologies, work and learning. Educational Research Review, 4 210-219.

Billett, S., Wärvik, G-B and Choy, S. (2018). "Concepts, purposes practices of integration across national curriculum”. In S. Choy, G-B. Wärvik, and V. Lindberg (Eds). Integration of vocational education and training experiences: Purposes, practices and principles.

Singapore: Springer.

Choy, Edwards-Groves and Grootenboer (2017). "Provoking a (Re)newed Frontier in Theorising Educational Practice". In P. Grootenboer, C. Edwards-Groves and S. Choy (Eds). Practice theory perspectives on pedagogy and education. (265-280) Singapore: Springer.

Choy, S. and Hodge, S. (2017). Teaching practice in Australian Vocational Education and Training: A practice theory analysis. In P. Grootenboer, C. Edwards-Groves and S. Choy (Eds). Practice theory perspectives on pedagogy and education (157-173). Singapore: Springer.

Fejes, A. Runesdotter, C. and Wärvik, G-B. (2016). Marketisation of adult education: principles as business leadres, standardised teachers and responsibilised students. International Journal of Lifelong Education. 35 (6): 664-681.

Henning Loeb, I. and Lumsden Wass, K. (2014). A policy of idualisation and flexibility ignoring the situation of non-self reliant individuals: The example of Swedish basic adult education. The Journal for Critical Education Policy Studies. 12 (2): 399-422.

Kemmis, S., Edwards-Groves, C., Wilkinson, J., and Hardy, I. (2012). Ecologies of practices. In P. Hager, A. Lee and A. Reich (eds.), Practice, learning and change. London: Springer, 33-49.

Kemmis, S. and Grootenboer, P. (2008). Situating practice. In S. Kemmis, and T.J. Smith (Eds). Enabling praxis: Challenges for education (pp. 37 -62). Amsterdam: Sense.

Kemmis, S. Wilkingson, J., Edwards-Groves, C., Hardy, I., Grootenboer P. and Bristol, L. (2014). Changing Pracices, Changing Education. London: Springer. 
Mahon, K., Fransisco, S. \& Kemmis, S. (Eds.). (2017). Exploring education and professional practice. Through the lens of practice architectures. Singapore: Springer.

Mahon, K., Kemmis, S., Francisco, S, and Llyod, A. (2017). Introduction: Practice theory and the theory of practice architectures. In K. Mahon, S. Francisco, and S. Kemmis, (Eds). Exploring education and professional practice: Through the lens of practice architectures (pp. 1 - 30). Singapore: Springer.

Lasonen J. and Teräs M. (2016) Teachers' intercultural competence as part of global competence. In: Welch A.G., Areepattamannil S. (eds) Dispositions in teacher education, pp. 221-233. Rotterdam: SensePublishers.

Lave, J. \& Wenger, E. (1991). Situated learning: Legitimate peripheral participation: Cambridge university press.

Nicolini, D. (2012). Practice, theory, work and organisation. Oxford: Oxford University Press.

Osando, G. and Billett, S. (2009). African students from refugee backgrounds in Australian TAFE institutes. A case of transformative learning goals and processes. International Journal of Training Research, 7 (2), 80 - 94.

Onsando, G. and Billett, S. (2017). Refugee immigrants' experiences of racism and racial discrimination at Australian TAFE institutes: a transformative psychologiacal approach. Journal of Vocational Education and Training. 69 (3). 333-350.

Prokic-Breuer, T. and McManus, P.A. (2016). Immigrant educational mismatch in Western Europe, apparent or real? European Sociological Review, 32 (3), pp.411-438.

Salant, B. and Benton, M. (2017). Strengthening local education systems for newly arrives adults and children. Empowering cities through better use of EU instruments. Paper produced for the Partnership on Inclusion of Migrants and Refugees, part of the Urban Agenda for the EU. Washington DC: Migra on Policy Instute Europe. 
Schatzki, T. (2002). The site of the social: A philosophical account of the constitution of social life and change. University Park, TX: University of Pennsylvania Press.

Schatzki, T. (2017). Practices and learning. In P. Grootenboer, C. Edwards-Groves and S. Choy (Eds). Practice theory perspectives on pedagogy and education. (265-280) Singapore: Springer.

Schatzki, T. Knorr Cetina, K. and von Savigny (eds.) (2001). The practice turn in contemporary theory.New York: Routledge.

Svensson, L., Ellström, P. and Åberg, C. (2004). Integration formal and informal learning at work. The Journal of Workplace Learning, 16 (8), 479-491.

Swedish Research Council (2017). Good research practice. Stockholm: Swedish Research Council.

Teräs, M. and Lasonen, J. (2012). The development of teachers' intercultural competence using a change laboratory method. Vocations and Learning. 6 (1). pp. 107-134.

Timmermans, J. A. (2014). Identifying threshold concepts in the careers of educational developers. International Journal for Academic Development, 19(4), 305-317.

Webb, S., Faine, M., Pardy, J. and Roy, R. (2017). The role of VET in the (dis)placing of migrants' skills in Australia. Journal of Vocational Education and Training. 69 (3), 351-370.

Wheelahan, L. and Moodie, G. (2017). Vocational education qualifications' roles in pathways to work in liberal market economies. Journal of Vocational Education and Training. 69 (1), $10-27$.

Wärvik, G-B. (2013). The reconfiguration of adult education VET teachers: Tensions amongst organisational imperatives, vocational ideals and the needs of the students. International Journal of Training Research. 11 (2). pp. 122-134. 
